\title{
Hospedajes históricos en torno al Santuario de Covadonga en Asturias
}

\author{
Gracia Suárez Botas \\ Universidad de Oviedo
}

\section{RESUMEN}

Partiendo de una trayectoria histórica singular asociada a un enclave vinculado al turismo religioso y de naturaleza, se analiza el desarrollo y las particularidades de unos hospedajes que van a ir surgiendo en torno a las necesidades de un santuario mariano que va a convertirse en centro del turismo de montaña con la creación del Parque Nacional de la Montaña de Covadonga, y al protagonismo de la iglesia en su gestión. El artículo se detiene en el análisis del hotel Pelayo, signo de identidad e icono del santuario.

\section{PALABRAS CLAVE:}

Santuario mariano, hospedaje, tipologías arquitectónicas, cabildo, naturaleza.

\section{ABSTRACT}

Taking into account a special historical background associated with a venue linked with religious and nature tourism, we analyze the development and features of the lodgings originated due to the Virgin Sanctuary which became a center of mountain tourism with the creation of The National Park of Covadonga Mountains. The article analyses "Pelayo Hotel" sanctuary icon and identity symbol.

\section{KEY WORDS:}

Sanctuary, lodging, architectural tipology, canonry, nature. 


\section{Aproximación a la historia del Santuario}

La gesta histórica de Pelayo en el año 722, punto de arranque de la Reconquista, será el catalizador de una devoción mariana que contará con el patronato regio y las ventajas de un enclave de singular belleza, que van convertir el Santuario de la Virgen de Covadonga en uno de los más importantes de la cristiandad. Naturaleza, historia y espiritualidad van a confluir de forma excepcional en este lugar constituyendo sus principales señas de identidad.

Situado en las estribaciones de los Picos de Europa, en el Parque Nacional de Covadonga, en un estrecho valle rodeado de majestuosas montañas de ricos matices calizos y frondosa vegetación de especies autóctonas como castaños, robles, fresnos, avellanos, nogales y lilos, alimentadas por un rico caudal de aguas, el santuario ha sabido integrar esta naturaleza exuberante y bella con la religiosidad de la devoción mariana. De este modo "la propia naturaleza se ofrece como un importante itinerario de iniciación religiosa para quién acude motivado por la fe, ya que a través de ella, el creyente eleva la mirada y el corazón a Dios". ${ }^{1} Y$ de este modo las obras que se acometieron en el santuario a finales del s. XIX para su renovación mantienen la cueva abierta y refuerzan los elementos naturales como la roca y el agua, permitiendo que el peregrino, a medida que se acerca al Santuario, pueda contemplar desde el camino la Gruta, y penetrar en ella, integrando así la fuerza de la naturaleza con la espiritualidad de la devoción.

También la historia juega en el lugar un papel fundamental y un mensaje que también es religioso. Porque hablar de Covadonga es hacerlo de Pelayo y de la firmeza con la que las crónicas ensalzan la resistencia de un grupo de cristianos y su caudillo Pelayo frente al enemigo musulmán. Aunque la batalla de Covadonga haya sido magnificada en las crónicas asturianas, sin duda significó un momento decisivo para Asturias y para España. En Covadonga nace Asturias como reino y como nación. Pocos años después, en el 737, el rey Favila, sobre un dolmen pagano edifica el templo de la Santa Cruz en Cangas de Onís y en el 740 ya existe constancia de un monasterio en Covadonga. ${ }^{2}$

1 TUÑÓN ESCALADA, Juan José, “El Santuario de Covadonga. Historia de una devoción”, en J. Rodríguez Alonso (ed), El Gran Hotel Pelayo de Covadonga, 19092009, Cien años de historia y turismo en el corazón de Asturias, C.H. Editorial, Oviedo, 2009, pp. 17-18.

2 RUIZ DE LA PEÑA SOLER, Juan Ignacio, La Monarquía Asturiana (718-910), Centro de Estudios e Investigación “Sap Usudiri”, León, 1995.
La escasa historiografía sobre la vida religiosa en Covadonga en el largo período medieval, nos habla de la existencia de culto en la Cueva a partir del s. VIII, atendido por una pequeña comunidad monástica, al estilo de las que por esos años existían en otros lugares de Asturias. ${ }^{3}$ Esta comunidad, que con el tiempo, pudo observar la regla de S. Benito, en el s. XIV se regía ya por la regla de S. Agustín, dependiendo de la autoridad del obispo según puede leerse en el Libro Becerro de la catedral de Oviedo:

"La abadía de Covadonga es de canónigos reglares pleno jure subjeto al obispo. Et el obispo ha de vesitar et corregir al abbad et convento et desque vaca la abadía eligen los monges et el obispo confirma. Et viene a los signnados et paga en todos los pechos et pedidos quel obispo echa a su clerezia et obedesçen et cunplen todas las ordenaçiones et mandamientos quel obispo faze" ${ }^{4}$

La recuperación que a partir de mediados del siglo XVI va a sacar de la pobreza al santuario, tiene mucho que ver con la protección de la Corona. El Patronato Regio resultó enormemente beneficioso para muchas iglesias, abadías y monasterios, especialmente para Covadonga por su especial significación en los orígenes de la monarquía y de la nación española. La visita que en 1572 hizo a Covadonga el bibliotecario real de Felipe II, Ambrosio de Morales, recogida en su Viage Santo a los Reynos de León y Galicia y Principado de Asturias, donde describe con minuciosidad la precaria situación del Santuario, sirve para marcar el arranque de esta decidida intervención de los monarcas en Covadonga. ${ }^{5}$ Desde entonces reyes y obispos con sus donaciones y obras de mejora y de reorganización del culto, consiguieron hacer de Covadonga uno de los santuarios nacionales de referencia.

En la noche del 17 de octubre del año 1777 se produce un desgraciado incendio que destruye

3 La historia del santuario está bien documentada en la reciente obra del grupo de investigación "Ceán Bermudez" de la Universidad de Oviedo: Nuestra Señora de Covadonga. Historia y patrimonio artístico, Oviedo, Trea, 2015, pp. 18-25.

4 Citado en TUÑón ESCALADA, Juan José, El Gran Hotel Pelayo de Covadonga, 1909-2009..., op. cit., p, 22.

5 CRABIFOSSE CUESTA, Francisco, "Evocación y memoria del santuario de Covadonga”, en Covadonga: iconografía de una devoción : exposición conmemorativa del centenario de la dedicación de la Basílica de Covadonga (1901-2001), Servicio Central de Publicaciones del Principado de Asturias. Gijón, 2001, 95-107. El autor analiza en esta contribución con detalle, el compromiso de la institución monárquica con Covadonga. 
el entonces conocido como "Templo del Milagro", o "Milagro de Covadonga" por devotos y peregrinos. ${ }^{6}$ Las llamas arrasaron por completo el corredor o galería de madera, incrustado en la roca de la cueva, con todos los enseres y objetos litúrgicos que contenía, incluida la imagen de la Virgen. Conmocionada la sociedad asturiana y española con el desafortunado incidente, el cabildo del Santuario y las autoridades regionales pronto acudieron al Consejo de Castilla en busca de apoyo y soluciones. Para ello es comisionado por el Cabildo de Covadonga y enviado a la corte el Abad Nicolás de Campomanes; al enterarse el Rey Carlos III, movido por el Conde de Campomanes, ordenó que se levantara un nuevo templo monumental; y por ello encargó a su arquitecto de cámara Ventura Rodríguez a que "pasase por Covadonga y levantase la planta de un edificio correspondiente a la celebridad del Santuario" delante de la cueva. Se hizo el presupuesto del proyecto de un templo monumental, que ascendió a la cantidad de catorce millones de reales. Ordenó entonces el Rey una cuestación por toda España con el fin de recaudar esa cantidad. Este proyecto de templo, grandioso y de arquitectura greco-romana, no se llevó a término. Las obras se inician en el mes de mayo del año 1.781 siendo encargada la construcción del mismo al arquitecto Manuel Reguera; ${ }^{7}$ sin em-

6 Sobre este primitivo templo de madera véase la descripción del cronista Ambrosio de Morales en Viaje de Ambrosio de Morales por orden del rey Phelipe II a los reinos de León y Galicia y Principado de Asturias, Biblioteca Popular Asturiana, Oviedo, 1977, (reedición facsimilar de la de Antonio Marín, Madrid, 1765, pp. 66-63; así como la de Luis Alfonso de Carballo en Antigüedades y cosas memorables del Principado de Asturias, Madrid, 1695, y la de Manuel Medrano en Patrocinio de Nuestra Señora de España. Noticia de su imagen del rey casto y vida del Ilmo Sr. D. Fr. Thomas Reluz, obispo de Oviedo, Francisco Plaza, 1719, pp. 58-63; CANELLA SECADES, Fermín, De Covadonga. Contribución al XII Centenario, Alvízoras Libros, 1998 (reedición facsimilar de De La Madrid, 1918) pp. VII-VIII; FERNÁNDEZ GONZÁLEZ, Ana María, "El templo colgante del monasterio de Covadonga", en Actas del Symposium Monjes y Monasterios Españoles, San Lorenzo del Escorial, 1-5 de noviembre, pp. 291-313; por otro lado el Diccionario de Madoz refleja la preocupación por la precaria situación del santuario a mediados del siglo XIX; véase MADOZ, Pascual, Diccionario Estadistico-Histórico de España y sus posesiones en Ultramar. Ámbito, Valladolid, 1985 (reedición facsimilar de De La Madrid, 1845-1850) p. 145.

7 Sobre este proyecto de Ventura Rodríguez, véase DE LA MADRID ÁLVAREZ, Vidal, La Arquitectura de la Ilus tración en Asturias. Manuel Reguera. 1731-1798, Ridea, 1995, pp. 219-233; DE LA MADRID ÁLVAREZ, Vidal, “E arquitecto Ventura Rodríguez y Covadonga; la accidentada historia de un proyecto frustrado", Liño, 15, 2009, pp.202-219; CHUECA GOITIA, Fernando, "Dibujos de Ven- bargo debido a la oposición del Cabildo "por ocultar la hermosura silvestre de la Cueva" y al elevado coste del mismo, la construcción no pasó de los cimientos, que son los que actualmente se encuentran al pie de la Cueva y sirven para canalizar el río Deva. ${ }^{8}$

El Concordato Isabelino del año 1851 que pone fin a las difíciles relaciones entre la Iglesia y el Estado, va a significar el punto de arranque de una nueva etapa en la historia del Santuario. Son años en los que Covadonga alcanzará su máximo desarrollo y esplendor gracias a la entusiasta y tenaz dirección de dos relevantes obispos ovetenses: don Benito Sanz y Forés (1868-1882) y Fray Ramón Martínez Vigil (1884-1904), que uniendo voluntades, lograron construir la gran basílica historicista en el cerro del Cueto, con cripta de Roberto Frassinelli y templo de Federico Aparici. ${ }^{9}$

\section{De la casa de Novenas al Gran Hotel}

La afluencia de romeros a los centros de peregrinación marianos y la necesidad de permanecer en ellos durante los nueve días que duraban los rezos y devociones previas, hacen necesaria la existencia de una "casa de novenas" para su albergue, siempre anexa a los lugares de culto. No va a ser Covadonga una excepción y al lado de la cueva, la colegiata de San Fernando se utilizará como casa de Novenas de este santuario. Muy pronto, las mejoras que a lo largo de los siglos se van a ir sucediendo, crearán nuevas necesidades y exigirán la creación de nuevos hospedajes en torno a la Santa Cueva, siempre bajo el patrocinio y la supervisión de la Iglesia.

tura Rodríguez para el Santuario de Nuestra Señora de Covadonga", AEA, 56 (1943), Madrid, pp.68-87; REESE, Thomas Ford, "V. Rodríguez, Jovellanos y Covadonga: proto-romanticismo en la España del siglo XVIII", $A E A, 197$ (1997), Madrid, pp.31-58; GONZÁLEZ SANTOS, Javier, "Las artes y las obras públicas asturianas en la época de la ilustración, Oviedo”, Instituto Feijóo de Estudios del siglo XVIII, Consejería de Cultura del Principado de Asturias, 1999, pp.58-63.

8 CRABIFOSSE CUESTA, Francisco, Covadonga: iconografía ..., op. cit., p.96.

9 Sobre el desarrollo de este santuario mariano y sus protagonistas véase ARBOLEYA MARTÍNEZ, Maximiliano, $L a$ basílica de Covadonga. Justificación de un doble homenaje, 1926, y MENÁNDEZ MORI, Paciente, El emmo Sr. Sanz y Forés (obispo de Oviedo. 1868-1882): algunos datos biográficos, Oviedo, 1928. La actividad pastoral de Ramón Martínez Vigil se resume en sus datos esenciales en la obra de BARRADO BARQUILLA, José, J. Fray Ramón Martínez Vigil, O.P. (1840-1904), Obispo de Oviedo, 1996. 
Tras la restauración del siglo XVII y durante el patronato regio de Felipe IV, se reforma el cabildo de Covadonga. El rey remplaza la primera comunidad de agustinos y crea un cabildo o Colegio Secular de Canónigos Seculares aumentando las dotaciones y el número de canónigos; fue entonces cuando se levantaron casas para fijar en el lugar a este clero, que antes no vivía en el santuario sino en la Riera, y se mandó construir una hospedería para albergue de los peregrinos. ${ }^{10}$

Un siglo más tarde se abre el Antiguo Mesón, edificio que aún se conserva, situado en el viejo camino de Covadonga, en la parte baja del jardín del Príncipe; donde parece salir al encuentro del viajero que llega al santuario. Fue mandado construir siendo abad Nicolás Antonio Campomanes Sierra y Omaña, bajo patrocinio de don Antonio de Estrada, quien decide que el producto de su renta fuera para la iglesia. Los cabildos capitulares incluyen detalles acerca de su explotación, como el de 18 de marzo de 1679 , donde puede leerse: "que convenía buscar persona que habite, viva y resida en dicha casa de mesón y tenga camas, pan, vino, hierba y cebada y más necesario para los del gremio de la iglesia y más personas que vienen en romería a visitar la sacrosanta imagen de Nuestra Señora". ${ }^{11}$ Bajo este mismo patrocinio se promovió también una calzada para carros desde la Riera hasta la explanada superior del santuario, terminada en 1777. Contaba ésta de dos puentes, uno sobre el Reinazo, bajo el molino y otro sobre el rio Orandi, bajo la Cueva; ${ }^{12}$ en la subida, junto a la colegiata, se construyó un canapé o banco de piedra, como parada de descanso. Ambas realizaciones destinadas a mejorar las infraestructuras vinculadas a los viajes, y facilitar así la llegada de romeros y peregrinos, en unos años en los que los medios de transporte se diversifican y transforman con la aparición de líneas regulares de diligencias. Este edificio del mesón mantiene la tipología de una casona tradicional asturiana, construida con buen sillar, con estructura de planta cuadrada, cubierta a cuatro aguas y dos amplios corredores volados, uno lateral y otro ocupando el cuerpo central sobre un

10 MENÉNDEZ PIDAL, Luis, La Cueva de Covadonga, Santuario de Nuestra Señora La Virgen María, Espasa-Calpe, Madrid, 1956, p. 127.

11 ACC. Libro de Acuerdos Capitulares, 1677-1690,f. 6r. Citado en Nuestra Señora de Covadonga ..., 2015, op. cit., p. 35.

12 Algunos detalles sobre la construcción de esta carretera en Nuestra Señora de Covadonga ..., 2015. op. cit., p. 3637; MENÉNDEZ PIDAL, Luis, La Cueva de Covadonga..., op.cit., p. 63. amplio zaguán al que se accede a través de un gran arco de medio punto. En su fachada, entre el arco y la solana, puede leerse la siguiente inscripción: "Este mesón se hizo/ siendoabad el SR/ don Nicolasanto/ Campomanes, Sierra y Omaña ano 1763". Dejó de utilizarse como hospedaje ya hace casi más de un siglo, convirtiéndose en los años veinte en cuartel para la Guardia Civil. Y ya en la década de 1950 fue restaurado por el arquitecto del cabildo Javier García Lomas, que respetó su tipología tradicional, con el fin de destinarlo a residencia de la escolanía de Covadonga. En estas obras de restauración y ampliación va a colaborar el pintor ovetense Paulino Vicente, autor de la decoración de los muros y puertas del zaguán y la escalera de este antiguo mesón. ${ }^{13}$

La fase de expansión y definitiva consolidación del Santuario, que arranca en la última década del siglo XIX va a ver aparecer nuevos edificios destinados a albergue de peregrinos así como a viajeros o turistas. La fonda del la Gruta, el hotel Pelayo y el hostal Favila serán los hospedajes de referencia en el Real Sitio durante las décadas en que el lugar se convirtió en uno de los principales centros marianos del catolicismo, a imagen de Lourdes o Fátima.

Las obras de Covadonga las inicia el Obispo de Oviedo, después arzobispo de Sevilla D. Benito Sanz y Forés en $1874 .{ }^{14}$ Paralizadas por falta de recursos en octubre de 1882, será su principal impulsor el obispo D. Ramón Martínez Vigil que "Encargó los planos, memoria y presupuesto de la nueva catedral al arquitecto D. Federico Aparici; terminó la sacristía interior o cripta; hizo el almenado que rodea al templo, con más el alto muro de la plaza y la grandiosa escalinata; levantó las otras casas capitulares y el palacio episcopal-abacial, la escuela, el cementerio, el hostal de Pelayo, y terminó en fin un nuevo pueblo en Covadonga"15.

También la mejora de las comunicaciones hacia el santuario sirvió para propiciar la masiva afluencia de peregrinos al lugar. Ya no eran aquellos esforzados romeros que después de días de

\footnotetext{
13 Ídem.p. 63

14 "Desde 1874 dispuso la construcción de las capillas del Campo, la de la Cueva y su escalinata; la reparación de la iglesia de San Fernando, el alcantarillado sobre el proyecto de Carlos III, la hospedería y dos casas altas de canónigos, (...) acordó los trabajos para volar la cuesta del Cueto, donde había de levantarse el templo monumental, abrió enseguida y llenó los comienzos de éste, levantó las paredes de la cripta hasta los arranques de los arcos y alzó dos casitas más para canónigos...”, en el Almanaque Asturiano del Carbayón para 1896, Oviedo, imp. de Vallina y Compañía y de Pardo, Gusano y Cía, p.79.

15 Ídem.
} 
dura caminata, llegaban al santuario llenos de fervor mariano, y no requerían de más lujos que la cama caliente y la exigua mesa que les ofrecía el antiguo mesón. Nuevas formas de viajar se imponen ahora con la llegada de líneas regulares de diligencias y especialmente con el desarrollo del ferrocarril. Fue clave en este sentido la apertura del la línea de ferrocarril de Arriondas al Repelao, relacionada con la explotación de las minas de hierro de Buferrera, financiada por la compañía inglesa que las explotaba. Desde este punto allí los viajeros tenían servicio de diligencia al santuario. Es en estos años y tras la llegada del ferrocarril a las cercanías de este lugar santo cuando se consolida la costumbre de celebrar las bodas en Covadonga. ${ }^{16}$

La Fonda de la Gruta, fue un hospedaje modesto, que vino a sustituir al viejo mesón ya citado, ante la necesidad de ampliar las plazas y mejorar el albergue de los peregrinos y visitantes. Construido en el último tercio del s. XIX bajo iniciativa del obispo D. Benito Sainz y Forés, y adosado a la antigua Colegiata de San Fernando, formaba con ella un cuerpo alargado anexo. Fue en este mismo lugar donde antaño se ubicaba la ya citada "Casa de las novenas". El historiador Menéndez y Pidal relata en este sentido como "Restaurados los lugares sagrados con sus dependencias y accesorios, Sanz y Forés dedica su atención a facilitar la permanencia del peregrino en el Santuario". Tal como describe don Félix Pío de Aramburu, en la obra Asturias, la construcción que se comienza en 1876 queda terminada en 1877: "Otra de las obras realizadas por el mismo Prelado fue la hospedería, obra indispensable en sitio tan visitado, y aunque la aludida construcción (consistente en un cuerpo estrecho y prolongado, que forma ángulo con la fachada principal de la Colegiata, y consta de planta baja, con cuadras y otras dependencias, y un piso alto dividido en habitaciones) es deficiente por su cabida y humilde en su interior como en lo exterior, fue la mejora muy oportuna y estimable". ${ }^{17}$ Existe también constancia del nacimiento de esta hospedería en el "Ángulo de 5 de febrero de 1877", donde se lee una comunicación del obispo fechada el 30 de enero que afirma: "y adjunto a ella un auto por el que se

16 Información oral ofrecida por José Juan Suárez Martínez. Sus padres se casaron en el santuario en 1907, utilizando como medio de transporte el tren y la diligencia, que les recogió en la estación del Repelao.

17 Este texto de Félix de Aramburu, para la obra Asturias de Octavio Bellmunt y Fermín Canella Secades, (18951900) aparece citado en MENÉNDEZ PIDAL, Luis, La Cueva de Covadonga..., op.cit, p. 127.

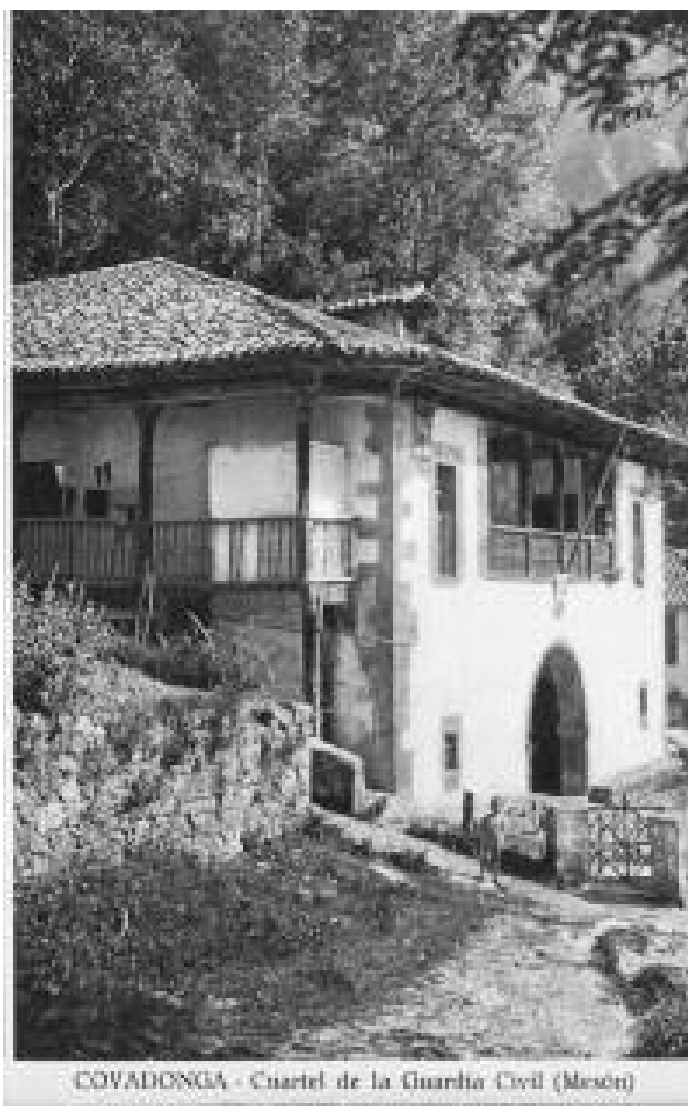

Fig. 1. El antiguo mesón en 1920. Archivo del Museo de Covadonga

erige e instituye la casa hospedería adyacente a esta Colegiata, declarándola bajo la administración del Cabildo y del Patronato de S.S.Y. y de sus sucesores en la silla de Oviedo. El Cabildo acordó contestar aceptando y acatando el auto y dando las gracias a S.S.Y". ${ }^{18}$ Pronto resultaron pequeños estos locales y en 1895 se decide instalar el comedor en la parte alta del claustro anejo a la hospedería. ${ }^{19}$

Por lo tanto, aunque en estos últimos años del siglo XIX se habían aumentado las plazas para el hospedaje y ampliado el comedor, para dar mejor asistencia al peregrino en el santuario, los nuevos tiempos requerían de servicios aún más exigentes. Unos, asociados al desarrollo de la higiene y del confort, otros, a la aparición de nuevos espacios de relación social. El viajero moderno demanda ahora renovados equipamientos en la fonda y en el hotel, establecimientos que por entonces habían desbancado a antiguos me-

18 ACC. Libro de Ángulos, 1862-190, f. 56.

19 ACC. Libro de Ángulos, 1862-1901, f. 159 (V). "El capitular Sr. García, administrador de la Hospedería, manifestó al Cabildo, que de acuerdo con el Excmo. Sr. Obispo, deseaba aprovechar la parte alta del claustro que está pegante a dicha Hospedería para destinarlo a comedor en la misma..." 
sones y posadas. Los últimos años del siglo XIX y los primeros del XX, ven aparecer un nuevo concepto de hospedaje; con sus cafés y comedores, con elegantes halls y confortables salones y gabinetes de lectura; con habitaciones provistas de agua corriente y baños, y con una buena mesa de cocina francesa y toques sofisticados. ${ }^{20}$ Y uno de los mejores exponentes de estos nuevos establecimientos, lo encontramos en el santuario de Covadonga, y en su hotel Pelayo. Es en estos años cuando se inicia bajo iniciativa y supervisión del cabildo, la construcción de este emblemático hotel y poco mas tarde del hostal Favila. La hospedería de la Gruta para entonces ya había cumplido su misión y el edificio se convierte en Casa Diocesana de Ejercicios Espirituales, tras una reforma que proyecta el arquitecto Luis Menéndez Pidal.

\section{El Gran Hotel Pelayo}

La construcción del hotel Pelayo fue especialmente significativa para la puesta al día y modernización del santuario, en cuanto a equipamientos hoteleros se refiere. La iniciativa está estrechamente relacionada con el conjunto de actuaciones ya citadas, llevadas a cabo en las últimas décadas del siglo XIX y los inicios del XX, que configuraron y potenciaron este gran centro de peregrinaciones marianas.

Construido siete años después que la basílica, y proyectado también por el arquitecto $\mathrm{Fe}-$ derico Aparici -se inaugura en 1909- va a cubrir la necesidad acuciante, y tantas veces reflejada en los escritos de la época, de que el santuario contara con unas infraestructuras de hospedaje acordes con los tiempos. ${ }^{21}$ Conviene mencionar aquí el papel fundamental que jugó la figura del financiero asturiano Policarpo Herre-

20 SUÁREZ BOTAS, Gracia, Hoteles de viajeros en Asturias, KRK Ediciones, Oviedo, 2016, pp. 67-97.

21 Federico Aparici y Soriano nació en Valencia en 1832. Estudió arquitectura en la Escuela de Madrid, terminando en 1855. Decano de todos los arquitectos españoles, fue profesor desde 1867 y dirigió entre 1896 y 1920, la Escuela de Arquitectura de la capital. Prestigioso profesional, ocupó muchos cargos tanto en la administración pública como en la enseñanza. Murió en Madrid, en 1917. En Enciclopedia Espasa. 1987, p. 685, t. 1, Apéndice. Su biografía en ZABALA GALLARDO, Manuel, "Don Federico Aparici", en la revista Arquitectura, n. 1, 1918, pp.713. El encargo de este proyecto a Federico Aparici por parte de la Comisión Provincial de Monumentos en sesión del 24 de marzo de 1884 aparece citado en MORALES SARO, María Cruz, Roberto Frassinelli, el alemán de Corao: Asturias (1845-1887), p. 122. ro, concediendo un crédito sin interés para la terminación de las obras del hotel. ${ }^{22}$ Y en 1908 , muy cerca ya de la finalización de las obras, se acuerda conceder la concesión del mismo a Enrique Alvarez Victorero, que estará al frente del hotel hasta 1930. Se convierte desde entonces este establecimiento, bajo las manos expertas de su primer concesionario, en un hotel de lujo. El cabildo, propietario del edificio fijará las condiciones del acuerdo de explotación desde el principio y continuará con la propiedad del hotel. ${ }^{23}$

Victorero fue una auténtica figura y un referente en el mundo de la hotelería de lujo. ${ }^{24}$ Hijo de Leonor Victorero de Álvarez, que había regentado un renombrado hotel en la calle Jovellanos de la capital, "La Colunguesa", fundado en 1875 y muy frecuentado por el clero, tras su paso por este hotel del santuario, se trasladó a Oviedo, donde abrió el "Café Peñalba" en el Pasaje, una verdadera institución en Oviedo como café elegante, y años más tarde, en 1935, el "Res-

22 ACC. Libro de Acuerdos Capitulares. 1872-1911. Cabildo ordinario del 10 de Noviembre de 1908, f.312.

23 ACC. Libro de Acuerdos Capitulares. 1872-1911. Cabildo ordinario del día 27 de abril de 1909, f. 321. "El Cabildo debe pensar en si ha de administrar por sí mismo la nueva Fonda o si ha de sacarla a subasta y habiendo acordado por unanimidad administrarla directamente, el trío da lectura a las bases que presenta D. Enrique Álvarez Victorero para la explotación de la misma y como encargado del Cabildo. Dichas bases con las modificaciones convenientes fueron aprobadas..." "Bases para el contrato que ha de celebrar el Cabildo con D. Enrique Álvarez Victorero (...) $1^{\circ}$. El contrato durará tres años, pero con obligación a seguir por dos más el mencionado Sr. Victorero si continuase con el contrato del Hotel Pelayo. $2^{\circ}$. Entregará al cabildo el 1er año, 900 pts., el 2º 9500, 1000, el tercero y otras 1000 cada uno de los dos últimos. (...) $7^{\circ}$. Será de cuenta del Sr. Victorero, la contribución, instalación de la tienda y de la luz eléctrica..." $8^{\circ}$. El Sr Victorero quedará con las existencias del cabildo (...), su importe lo abonará (...) $9^{\circ} \mathrm{El}$ cabildo quedará con la instalación cuando termine el contrato ...."

24 “Don Enrique Álvarez Victorero era un auténtico enamorado de la hostelería selecta. Había empezado su actividad de empresario hotelero en el Pelayo, de Covadonga, que tuvo arrendado durante veinte años. Dominando perfectamente seis idiomas, viajaba con mucha frecuencia por Europa con ánimo, exclusivamente, de conocer hoteles y restaurantes y perfeccionar, en lo posible, los servicios en sus establecimientos. (...) Hablar de don Enrique Victorero era una garantía de servicio, de seriedad y de trato... Entre muchos de los banquetes servidos se recuerda uno ofrecido en Madrid por un marqués asturiano, al que asistieron tres mil personas al aperitivo y mil quinientas a la comida. Se llevó todo desde Oviedo en un servicio especial del ferrocarril, con toda la plantilla de camareros del Peñalba y del Casablanca." En ARRONES PEÓN, Luis, Historia y Anécdota. Hostelería del viejo Oviedo. Recopilación de reportajes publicados en el diario la Voz de Asturias desde abril de 1973 a febrero de 1974, Ayuntamiento de Oviedo,1997, pp.229-230. 


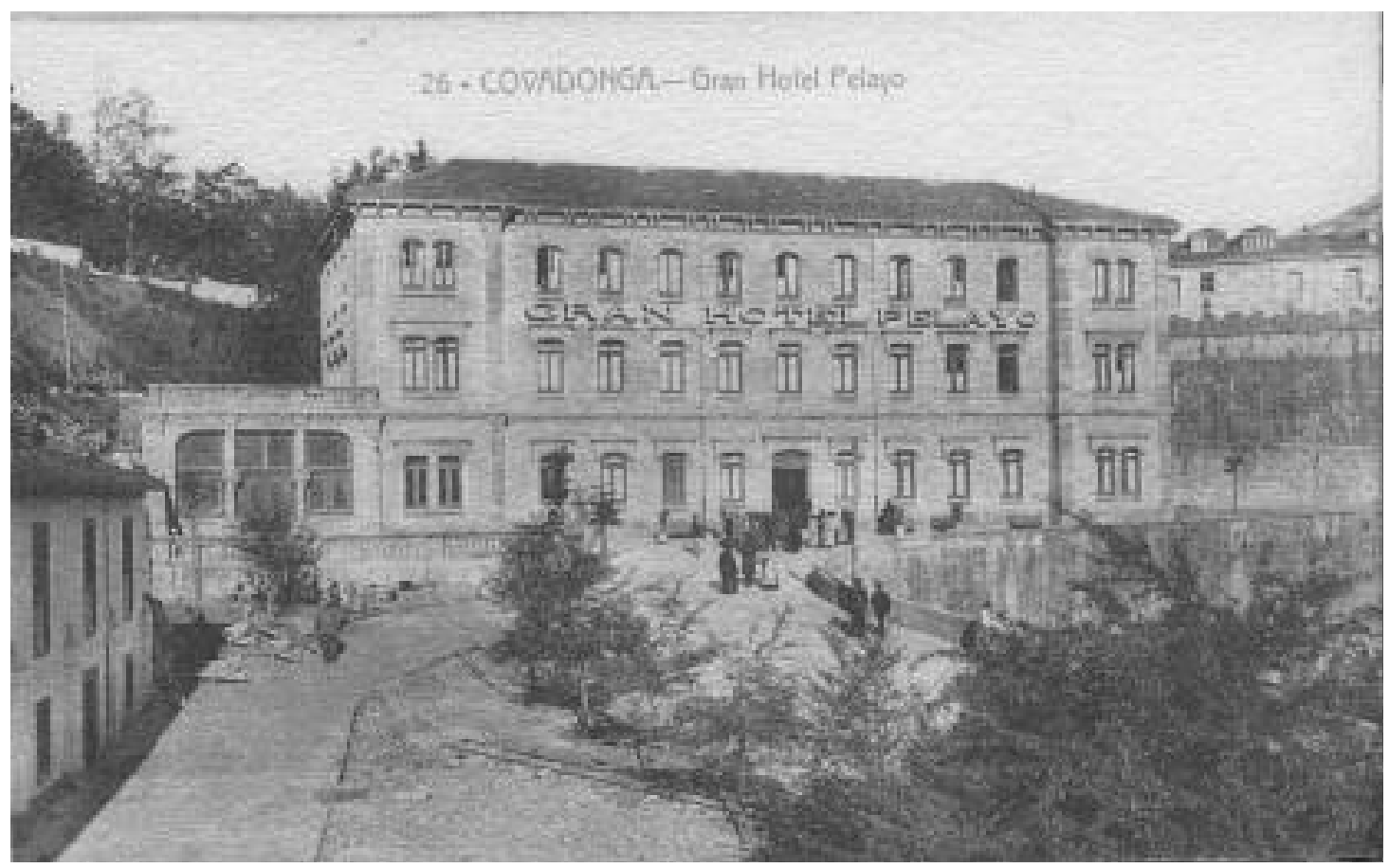

Fig. 2. Fachada principal del hotel Pelayo. Tarjeta postal

taurante Sisters", que tras la guerra se convirtió en el Casablanca, auténtico establecimiento de lujo, uno de los mejores de España en esta época. Así describe el hotel Pelayo y a su director la Guía Turística de referencia del año 1924, la de Pérez Pimentel:

"Hotel soberbio, a tres horas de la cumbre de Peña Santa, al pie de los Picos de Europa, en pleno Parque Nacional, con precios de Oviedo y Gijón; mejor atendido que muchos de la Corte; excelente cocina y exquisita repostería; cave de primera y su dueño, émulo de Brillant-Savarin, políglota, alpinista enragé, dilettanti...y ainda mais, no es cosa para pasarla en silencio. En ciudades de importancia no es fácil hallar todas estas condiciones reunidas en un Hotel. Así se explica el asombro de los viajeros, ante hotel y hostelero. El Hotel Pelayo y su Gerente, son dignos uno de otro!".25

También la guía turística de Nava Valdés del año 1915, dedica unas palabras muy elogiosas a la figura de Victorero:

"Covadonga cuenta con el magnífico "Hotel Pelayo", regentado por D. Enrique Victorero, uno de esos hombres que poseen el talismán de

25 PÉREZ PIMENTEL, Antonio, Asturias, Paraíso del Turista, Editorial Covadonga, Gijón, 1924, p.186. hacerse simpáticos. Es gran sportman, viajó continuamente, y como alpinista infatigable decidió vivir en un verdadero centro para hacer gratísimas las horas a los que tienen la dicha de visitar estos lugares. Esta es una nota interesante para el turista." 26

El periodista Gabriel Briones en la revista Covadonga, ( $\mathrm{n}^{\circ}$ 6) del 1 de septiembre de 1922 en su artículo "El espíritu descansa en Covadonga", ofrece su visión de un hotel, organizado en forma tal, que los viajeros disfrutaban de las mismas comodidades que en cualquiera de los hoteles suizos, servidos por ferrocarriles y funiculares, aunque en el Pelayo la vida era "más sencilla, cómoda e independiente que en los países alpinos o en las orillas de los lagos helvéticos”. Por las mañanas los alojados en el hotel solían ir a la Cueva de la Virgen para orar, oír misa, ver el sepulcro de Pelayo; a la basílica, donde escuchaban la música que salía de los acordes del órgano, mientras que otros organizaban la excursión del día. Continúa su evocador relato contando cómo en el salón de lectura, no existían periódicos nacionales ni extranjeros, sino solamente revistas y libros de excursiones, ya que el Gerente, D. Enrique Álvarez Victorero, pen-

26 NAVA VALDÉS, Antonio, Turismo-Asturias. Guía para el turista, Talleres Gráficos de Ramiro P. del Rio e Hijo, Luarca, 1915, p. 99. 
saba en los efectos desagradables que podían producir las malas noticias cuando alguien se encontraba de vacaciones.

Muy pronto el establecimiento se va a convertir en algo más que un excelente hotel que daba un buen servicio a los peregrinos y visitantes devotos que frecuentaban el santuario. Será sede y centro del Parque Nacional de la Montaña de Covadonga, creado en 1918 y por tanto centro de turismo de naturaleza en el incomparable marco de los Picos de Europa. Y es precisamente un 8 de septiembre de este año, coincidiendo con los actos de conmemoración del XII centenario de la batalla de Covadonga, cuando se celebrará la solemne inauguración de este Parque en las instalaciones del hotel, con la presencia del rey Alfonso XIII y la reina Victoria Eugenia. Puede decirse con rotundidad que el turismo de naturaleza se inició en España con la creación de este Parque Nacional y que ello va a estar estrechamente ligado a las iniciativas y a la actividad del hotel Pelayo. Excursiones de montaña en los coches del hotel a los lagos y a otros puntos de los Picos de Europa, promoción a través de colecciones de postales que se vendían en la tienda de este establecimiento hotelero y la propia oficina del Parque instalada en sus locales, son algunas de las pruebas que hablan de la estrecha vinculación que va a existir entre este espacio natural y el hotel; y que se explica muy bien conociendo la relación de parentesco entre Victorero y Pedro Pidal, principal impulsor del proyecto, dado que eran cuñados. ${ }^{27}$

Las actas de las periódicas reuniones del cabildo, contienen abundante información de los contratos de Victorero con la iglesia, sobre sus condiciones y exigencias, reflejando una buena relación entre ambas partes. ${ }^{28}$ Las obras de man-

27 GONZÁLEZ, Luis Aurelio, "El gran Hotel Pelayo, referente esencial en los albores del turismo de Asturias y de la hostelería en España”, en RODRÍGEZ ALONSO, Jaime, (ed), El Gran Hotel Pelayo de Covadonga, 1909-2009, Cien años de historia y turismo en el corazón de Asturias, CH Editorial, Oviedo, 2009, pp. 80-87.

28 ACC. Libro de Acuerdos Capitulares. 1912/1918. Cabildo extraordinario de 1913, ff.11-13. En 1913, y tras rescindirse el contrato, Victorero propone al cabildo las siguientes bases: "Acabamiento del 3er piso del hotel. Reparación los techos y tejados del Hotel y Hospedería. Modificación del servicio de aguas en los pisos $1^{\circ}$ y $2^{\circ}$ del Hotel. Construcción de una escalera de servicio. Pintura exterior de puertas y ventanas del Hotel. Prolongación de la despensa y habilitación de nueva carbonera. Habilitación de un departamento limpiabotas debajo de la escalera. Apertura de una puerta y derribo de dos tabiques en la planta baja del Hotel. Paso cubierto por el patio desde la cocina al comedor de los criados. (...) En cuanto a la ejecución de las obras que solicita el Sr. Victorero, el Cabildo tenimiento del edificio serán por cuenta del cabildo y las puramente hoteleras del arrendatario. Por poner un ejemplo, en 1916 se acuerda construir un garaje para automóviles, habida cuenta que ya se habian adquirido para el hotel un Panhard, un Lorraine Dietrich y un Studebaker ${ }^{29}$, al ser el establecimiento centro de excursiones, y especialmente debido al aumento de clientes que se desplazaban por este nuevo medio de transporte. ${ }^{30}$ En cuanto al garaje, "El Sr. D. Enrique Victorero presta los fondos necesarios sin interés alguno mientras sea arrendatario del hotel" y "lo que se recaude por alquiler de los coches será repartido por partes iguales por el cabildo y el Sr. Victorero." En el nuevo contrato que se firma en 1921 el arriendo pasa a 20.000 pesetas y comprende también la hospedería. Enrique Álvarez Victorero estuvo al frente del hotel hasta el año 1930. Le va a sustituir don Julián del Oro, que antes había sido jefe de cocinas en el hotel Palace de Madrid. ${ }^{31}$

Esta estrecha vinculación del hotel con la iglesia, que tiene sus antecedentes remotos en las tradicionales casas de ánimas que daban habitación a los romeros en la totalidad de los santuarios marianos, va a marcar también la fisonomía del edificio; especialmente por la utilización en la fábrica de sus muros de la misma piedra de la basílica, la caliza de Peñalba, que con su bello veteado y tonalidad rosácea, va a conferir un toque especial a una arquitectura estrictamente funcional, proporcionándole una clara uniformidad formal respecto al resto de las construcciones del Real Sitio. También sus instalaciones estaban a la altura de un hotel de lujo. Se hallaba enclavado en una segunda explanada, algo más abajo que la del templo, muy cerca del arranque del camino hacia la gruta. El privilegiado emplazamiento ofrecía a los viajeros allí hospedados contemplar desde sus instalaciones la mejor panorámica de la basilica y de la naturaleza circundante, siendo ade-

nombró una comisión de su seno (...), al que dio el encargo de practicar una inspección ocular y un estudio acerca de las obras que debían realizar, de todo lo cual daría cuenta el cabildo en la próxima sesión..." Se decide asimismo que corren a cuenta del cabildo estas obras: la reparación de tejados y techos, el arreglo de la terraza, pintura en carpinterías, terminación del tercer piso, arreglo de la instalación de aguas y construcción de una escalera de servicio. Las restantes serán a cargo del arrendatario.

29 PÉREZ PIMENTEL, Antonio, Asturias Automovilística, Talleres Tipográficos la Fé, Gijón, 1923, pp. 5-6.

30 ACC. "Cabildo extraordinario del 23 de junio de 1916". "Libro de Acuerdos Capitulares". 1912/1918, f. 20.

31 MENÉNDEZ PIDAL, Luis, La Cueva de Covadonga..., op. cit. p. 174. 


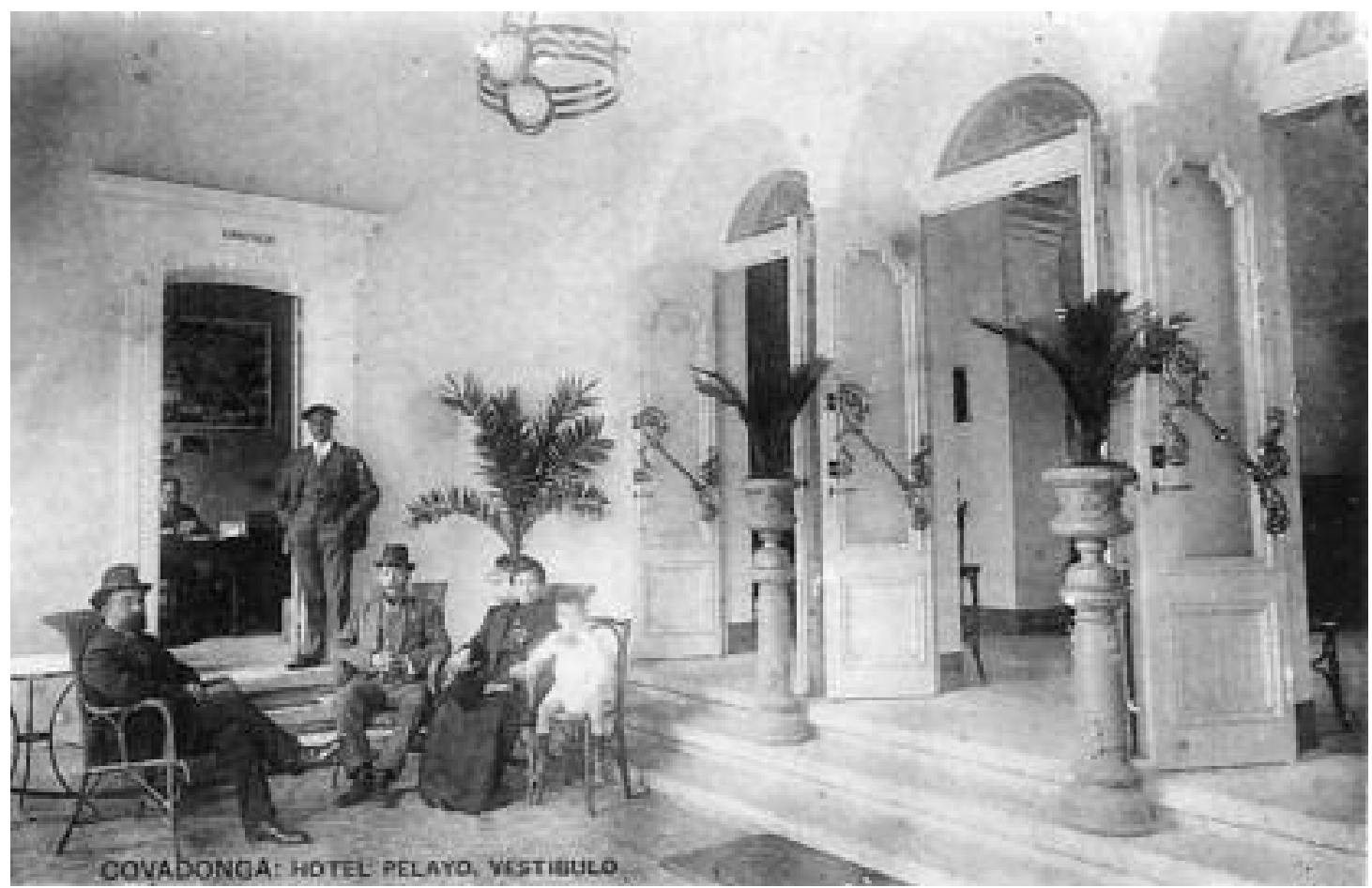

Fig. 3. Vestíbulo del hotel. Archivo del Museo de Covadonga

más paso obligado de la "vía sacra" en el recorrido de las procesiones por el santuario.

Respecto a la arquitectura del edificio, decir en primer lugar que el proyecto de Aparici iba a seguir en su disposición y composición esquemas de funcionalidad ajustados a un tipo de planta en $\mathrm{H}$ con los brazos apenas desarrollados; resultando una planta rectangular con unos extremos ligeramente destacados. Una tipología edificatoria muy utilizada en hoteles de nueva planta asentados fuera de áreas urbanas, que es la que proyecta García Lomas también para el cercano hostal Favila y que tiene su precedente en modelos muy utilizados en la arquitectura europea. En Le Recueil d Arquitecture. Choix de documents pratiques. Publication mensual sous la direction de William et Farge, uno de los tratados franceses de la segunda mitad del XIX que marcan las pautas de la arquitectura del momento, aparece un hotel de viajeros dentro de las "Constructions industrielles" que presenta una organización lineal muy parecida con planta en $\mathrm{H}$, alargada y con los brazos cortos, con un cuerpo central destacado. En el caso del Pelayo este cuerpo se corresponde con la caja de la escalera y sólo se destaca en la fachada posterior. ${ }^{32}$ Constaba el edificio original, de planta baja, dos pisos y bajocubierta abuhardillado. Los planos que se con-

32 SUÁREZ BOTAS, Gracia, Hoteles de viajeros..., op. cit, pp. 203-204. servan de este edificio son los de Sainz Vicuña de la reforma de 1961, y pueden servir para analizar la configuración general del edificio primitivo. ${ }^{33}$ Existen también informes técnicos exigidos por la Dirección General de Turismo que describen las dependencias y equipamiento del hotel en el año 1946.

En el lado izquierdo se había añadido un cuerpo de una planta a modo de pabellón, con cubierta plana en la terraza rematada con balaustrada de piedra; lugar donde se encontraba el comedor principal o de banquetes. La práctica totalidad de esta fachada la ocupaba una cristalera cerrada con puertas de perfiles mixtilíneos y un reticulado de hierro protector con motivos florales. Dividían este gran vano rematado en arco rebajado, dos pilastras sobre columnas muy decorativas con abultados follajes en sus capiteles. Este era el lugar preferido de los numerosos novios para realizar las fotos de grupo, en las numerosas celebraciones nupciales que allí se realizaban.

La composición clasicista de las fachadas se basa como suele ser habitual, en la colocación de los vanos en ejes simétricos, agrupados en grupos de tres, dividiendo el cuerpo longitudinal, y dos en los cuerpos avanzados de los extremos. El

33 AGPA. Dirección General de Turismo. "Manuel Sainz de Vicuña. Arquitecto. Reforma en el Hotel Pelayo. Covadonga. Planos. Julio 1961”. Exp. 15936/2. 
embellecimiento de la construcción se consigue con la decoración de aire historicista de dichos vanos, utilizando también algunos elementos decorativos existentes en la cercana basílica, como las bolas bajo el guardapolvo y los rollos bajo arco rebajado que apoya a su vez en ménsulas en voladizo. Se trata de una ornamentación que se refuerza en los vanos de la planta baja y en la entrada principal. Sobre el primer piso y ocupando casi la totalidad de la fachada principal, se encontraba el letrero del "Gran Hotel Pelayo". La característica piedra de Peñalba asoma en las esquineras, líneas de imposta y adorno de los vanos. El resto de los muros aparecen enlucidos en tono gris, color que ha ido manteniéndose durante todas las reformas del edificio.

El acceso principal se sitúa en el centro de la fachada, aunque existe también otra comunicación directa al comedor de banquetes. Traspasando la entrada, un amplio vestíbulo con una triple arquería de medio punto que guardaba unas proporciones análogas a las existentes en la fachada principal de la basílica, daba paso al hall del hotel. Al fondo se encontraba el mueble de recepción. En esta planta se disponían también los comedores, las cocinas, y el salón social, con un departamento de joyería para la venta de material religioso. ${ }^{34}$

Con la caja de la escalera en el centro de edificio sobresaliendo sobre el frente trasero, la distribución de las habitaciones en las dos plantas de pisos era la siguiente: un ancho pasillo central al que daban a uno y otro lado el conjunto de las habitaciones, todas exteriores; algo fundamental teniendo en cuenta el discurso higienista de la época, que afirmaba que el aire viciado de los interiores era considerado como la causa directa de todo tipo de epidemias y enfermedades más comunes. La planta abuhardillada se destinaba a habitaciones del servicio. Tenía entonces el hotel treinta habitaciones, doce con cuarto de baño (con dos puertas, podían dar servicio a dos habitaciones), mientras que el resto contaba con un lavabo de agua caliente y fría. No había en esos años teléfono en las habitaciones, ni tampoco calefacción central, y el hotel se cerraba durante la temporada de invierno. Aunque hoy parezca anacrónico, no dejaba de ser un lujo la existencia entonces de este número de cuartos de baño en una época en que se está produciendo una revolución en el mundo de la higiene. Conviene tener en cuenta que en España sólo algunos de los hoteles de gran lujo con-

34 AGPA. Ídem. taban con esta instalación. En 1906 el Ritz de París por ejemplo, tenía un baño para cada habitación, y lo mismo ocurría con el Palace de Madrid, que se inaugura en 1911. No era sin embargo lo habitual, y el detalle de este hotel madrileño fue visto en la época casi como una extravagancia, pues el hotel Ritz madrileño inaugurado unos meses antes, justo enfrente del Palace, contaba sólo con la mitad de esta proporción. $^{35}$

Respecto al estilo decorativo de los interiores del hotel Pelayo, sigue la línea de la arquitectura historicista de aires medievales con cierto toque monacal, destacando la perfecta integración de las artes menores en la arquitectura del edificio. Merece así especial mención la barandilla de la gran escalera central, con un espléndido trabajo de forja que enlaza con una época marcada por la renovación de las artes y oficios artísticos que había iniciado William Morris y el movimiento de Arts and Crafts en las últimas décadas del siglo XIX. Presenta esta balaustrada el mismo motivo que los reposa-manos de la escalera del hall; un diseño vegetal a base de roleos formados por vigorosos tallos engarzado en originales piezas en forma de flecha. El mundo de la fantasía medieval se manifestaba también en los veladores zoomorfos de madera que todavía hoy adornan la escalera del hotel. Las carpinterías de las puertas de entrada al comedor de banquetes o de acceso al hall con sus formas mixtilíneas, sus cristales esmerilados y sus reticulados de forja, o el tallado del zócalo del comedor de banquetes con su filigrana decorativa, son también buen ejemplo de este resurgimiento y desarrollo de los oficios artísticos en estos años.

La foto del vestíbulo descubre una de las estancias más agradables del hotel, punto informal de encuentro y de reunión social con confortables canapés de junco y madera curvada tipo thonet, y decorativos floreros donde las horas pasaban de forma apacible charlando y contemplando el paisaje. Este lugar recuerda a muchos otros halls o vestíbulos de tantos hoteles de la época, siempre caracterizados por un mobiliario de mimbre y vegetación de palmeras. Las plantas contienen una clara simbología en la jardinería de entre-siglos asociada a la ostentación, la salud y la permanencia de las cosas. ${ }^{36}$ Se trataba de recrear un ambiente de naturaleza, a

\footnotetext{
35 DENBY, Elaine, Grand Hotels, Reality and Illusion, An Architectural and Social History, Reaktion Books, Londres, 1998, p.252.

36 BARALLAT, Celestino, Principios de botánica funeraria, Alta Fulla, Barcelona 1855, pp. 10-13.
} 


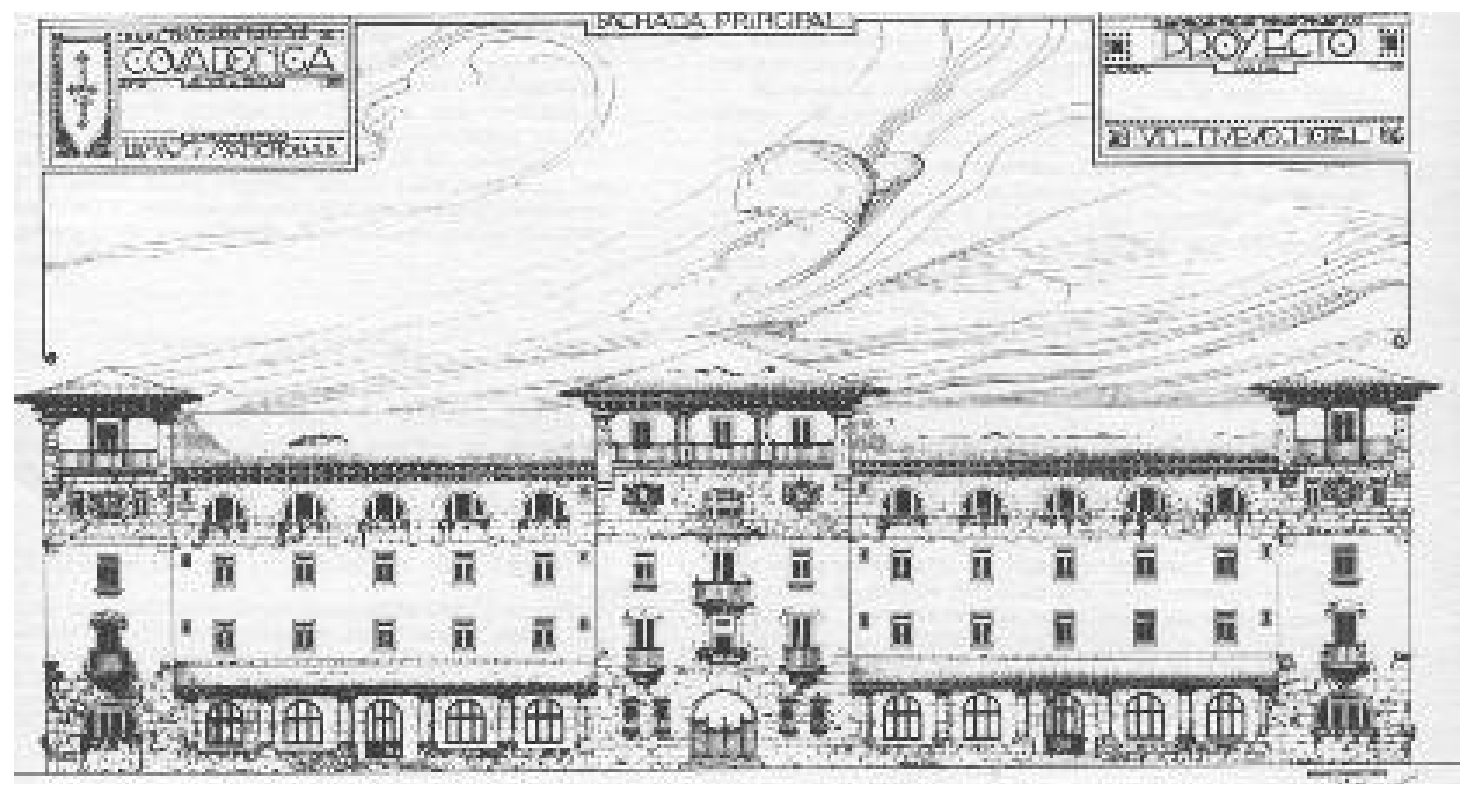

Fig. 4. Proyecto del hostal Favila. Fachada principal. Archivo Capitular

modo de un "jardín de invierno", en espacios luminosos con plantas y con animales disecados, en un deseo de introducir la naturaleza, el sol y la luz en el interior del hotel. Aquí la presencia de estas piezas del mundo animal -rebecos, águilas-, especialmente el oso, es mayor por la vinculación del hotel a la caza en el Parque Nacional de Covadonga. No hay que olvidar que el oso recuerda a aquél que las crónicas cuentan que mató al rey Favila. Fue un regalo de Pedro Pidal a Enrique Victorero y con el tiempo se ha convertido en un recuerdo imborrable para todas las generaciones de niños que desde entonces han traspasado las puertas del establecimiento.

El resto del mobiliario seguirá la misma línea historicista de su arquitectura y se recurre a la robustez y sobriedad del estilo español o al inglés del renacimiento, con maderas oscuras de roble y relieves de tradición plateresca o abultados torneados. Como bien se aprecia en uno de los espacios mejor conocidos, la tienda-joyería, con su mostrador y su armario vitrina, con su variado y sugestivo repertorio de recuerdos del santuario, un lugar especial que también se ha fijado en la memoria de muchas generaciones. El hotel también contaba con muebles de tradición popular asturiana. En las habitaciones existía una total coordinación entre todas las piezas: cama, mesitas, armario y colgador, muy habitual en los hoteles de la época, que guardaban el mismo estilo decorativo. La presencia de cuadros de gran formato, que tiempo atrás estaban en la colegiata, representando a los reyes asturianos, y que pasan a decorar salones y zonas de relación, da- rán el toque histórico a la atmósfera del hotel. Pertenecen a la Serie Cronológica de los Reyes de España depositados en el santuario en los años ochenta del siglo XIX. ${ }^{37}$

\section{El Hotel Favila y la Fonda La Roxa}

El imponente edificio del hostal Favila, -que en la actualidad alberga el museo de Covadonga- formó también parte del conjunto de actuaciones encaminadas a potenciar este santuario asturiano, dotándolo de unas infraestructuras de alojamiento capaces de competir con otros grandes centros marianos del momento. El aumento de peregrinos y visitantes al Real Sitio, y la potenciación del lugar como centro de turismo, por el recién creado Parque Nacional, hacían cada vez más necesaria la creación de un establecimiento destinado a clases medias y populares, que hasta ahora contaban como única hospedería la ya citada fonda de la Gruta, instalada en la Colegiata de San Fernando, dado que el hotel Pelayo, inaugurado en 1909, estaba destinado a un turismo más elitista por estar montado como hotel de lujo. Esta necesidad queda claramente reflejada en numerosos textos de la época como el escrito por el que fue pionero del turismo asturiano, Pérez Pimentel:

37 FERNÁNDEZ GARCÍA, Ana María, "Iconografía de los reyes asturianos: la colección de retratos del Real Sitio de Covadonga", Cuadernos de Arte e Iconografía, Madrid, 1993, t. IV, num.12, pp.367-375. 
“...Covadonga reclama con urgencia la satisfacción de tres necesidades. Necesidad primera: Hospedajes! Segunda: Hospedajes! Tercera: Hospedajes! Antes de terminar el Hostal Favila, obra grandiosa, urge hacer albergues rápidos: desmontables si preciso fuera. Hoy, el viajero rico, encantado; el vanidoso, item; pero... ¿y el pobre a quién el corazón mueve a estar días y días saturando su alma de paz en aquél Santuario y el bolsillo obliga a estar cuatro horas solamente? Y... unos y otros, en días señalados ¿dónde se albergan?..." 38

El proyecto de este edificio, que pretendía albergar cerca de 200 personas, se debe a los arquitectos del santuario Miguel G. Lomas y Urbano Manchobas. Si los planos y la memoria son del año 1920, el edificio no se inaugura hasta 1931, lo que refleja la magnitud de esta empresa y la lentitud de unos trabajos ralentizados principalmente por problemas de financiación, ya que fueron exclusivamente sufragados con limosnas y donativos. ${ }^{39}$ Se levanta en la explanada de la basílica, en el "Cueto", a continuación de las casas de los canónigos. La memoria del proyecto además de proporcionar los interesantes planos de un edificio construido para hotel, explica las razones, que a juicio de los arquitectos, decidieron la elección de este emplazamiento:

"Existe en Covadonga un factor que influye decisivamente en el emplazamiento de los edificios y es el carácter del lugar, (...) Más siendo las exigencias de nuevas construcciones, deben éstas ocupar un lugar discreto (...) La proximidad a la Cueva y Basílica se requiere para facilitar a los peregrinos la asistencia a los cultos. La proximidad a la zona habitada por los Canónigos es requerida por la vigilancia.(...) El único lugar que reúne las condiciones expuestas es el elegido (...) La fachada posterior de un edificio allí emplazado tendrá vista desde la estación y al comienzo de la cuesta; pero no alterará la contemplación aislada de la basílica, que puede efectuarse momentos antes de llegar el tren al Repelao (...) En las restantes fachadas, y muy especialmente en la Nor-

38 PÉREZ PIMENTEL, Antonio, Asturias, Paraíso...op.cit., p. 186.

39 "Durante el verano de este año, el día 9 de agosto, se inaugura el hostal Favila, para peregrinos modestos que visiten el Santuario. El nuevo edificio fue proyectado por los arquitectos García Lomas y Manchovas, habiendo terminado las obras, con don Miguel García Lomas, el arquitecto valenciano señor Martí.", en MENÉNDEZ PIDAL. Luis, La Cueva de Covadonga..., op. cit. p. 178. te, las vistas son espléndidas, contribuyendo a ello la conformación del terreno elegido...." ${ }^{40}$

El edificio, de claro estilo regionalista, tiene planta rectangular, con cuatro cuerpos salientes en los extremos y uno central que se prolonga hacia la fachada norte con un remate curvo, que le confiere aspecto de nave. Los cuerpos citados, con su terminación en torre, y sus cubiertas a cuatro aguas con pronunciado vuelo, a lo que se suma el clásico corredor de madera entre cortafuegos, confieren al edificio su marcado estilo. Consta de planta baja, y tres pisos, sin contar con la altura adicional que aportan las torres. Cuenta también con una planta de sótano que se abre hacia la fachada norte, donde se levantan cinco alturas. Presenta un original tratamiento de vanos, que son de arco de medio punto en la planta baja y en el último piso, y adintelados en los dos pisos intermedios. La planta principal hacia la explanada está recorrida por un pórtico ciego columnado, en donde se abren los arcos de las ventanas. La fábrica de los muros, muy en consonancia con la tipología del edificio, utiliza el sillar almohadillado con un acabado rústico.

La fachada norte, con un original cuerpo curvo central, donde se ubicaban las antiguas cocinas y el salón, se articula al exterior con altos contrafuertes en su parte inferior y con un corredor perimetral al que se accede a través de los ventanales del salón. La entrada principal se encuentra en el eje de la edificación. El conjunto de los espacios de servicio del hotel se concentraban en la planta de sótano. En un ala se disponían los dormitorios de criados, en la otra las dependencias relacionadas con el lavado y planchado de ropa, y en el centro la cocina y sus dependencias auxiliares. En la planta baja se encontraban las dependencias sociales alrededor de un gran vestíbulo distribuidor; en el ala este el salón y el café, y en el oeste un comedor dividido en dos grandes compartimentos. Y en las tres plantas superiores, las veintiséis habitaciones del hotel, con una capacidad para cincuenta camas.

El establecimiento se monta con sencillez y confort aunque sin lujos, pues estaba destinado a un público popular y de clase media, y preparado para alojar a un gran número de personas, utilizándose con frecuencia como residencia y lugar de celebración de ejercicios espirituales. De este

40 ACC. "Hostal Favila. Covadonga. Miguel García Lomas y Urbano de Manchovas. Arquitectos. Junta de Obras del Ilustrísimo Cabildo de la Colegiata Basílica”. [Memoria y Planos].1929. 
modo el comedor, dividido en dos compartimentos, podía servir en uno, noventa y un cubiertos y en otro, cuarenta y cuatro, dispuestos en una gran mesa longitudinal. El salón, que ocupaba el cuerpo saliente del Norte, de forma curva, y con espléndidas vistas, de grandes dimensiones, contaba con chimenea, rincón de música, y mesa de conferencias. Las habitaciones, de pequeño tamaño, se amueblaron con dos camas, un armario, lavabo, una mesa de noche, dos sillas y un tablero para escribir, bajo la ventana.

La sencilla decoración deja vistas las vigas y carreras, acusándose así las estructuras de techo, "con una molduración apropiada y en carácter con las tradiciones del país”. Del mismo modo se decorarán también las zapatas y canecillos, construidos con madera natural. El pavimento será de baldosa roja cocida con recuadro de azulejo y madera en el comedor. ${ }^{41}$

El cabildo, propietario del inmueble, va a arrendar su explotación. No debió de ser fácil su andadura, por el tamaño del inmueble y la necesidad de ofrecer unos precios económicos, por lo que muy pronto surgieron problemas que llevaron a su utilización primero como Seminario Menor, y después como residencia de la Escolanía. Existe un contrato de arrendamiento que se firma en abril de 1940 y que se rescinde en octubre de ese mismo año entre el cabildo y Encarnación Fernández Doral, (propietaria del Hotel Principado de Oviedo), para llevar el hotel Pelayo y el hostal Favila. La falta de entendimiento se produce por desacuerdos con el servicio que debía darse en este hostal, que no era el que pretendía la arrendataria. ${ }^{42}$ En la actualidad el gran edificio del hostal Favila alberga el Museo de Covadonga.

Finaliza este recorrido por tan emblemáticos hospedajes, con la fonda La Roxa, situada en la entrada al recinto del Santuario. Su origen se remonta a los últimos años del siglo XIX, cuando Covadonga solo contaba con esta hospedería, que propiedad del cabildo, había sido construida al mismo tiempo que se realizaban las obras del camarín de la Santa Cueva a instancias del obispo Sanz y Forés. ${ }^{43}$ En la actualidad $\mathrm{y}$ tras varias reformas continua en actividad con

41 Íbidem.

42 ACC. "Hoteles del Real Sitio de Covadonga. Contrato de 1940 y su rescisión”. 1940.

43 GONZÁLEZ, Luis Aurelio, "Un gran hotel como elemento revitalizador de la renovación material y espiritual de Covadonga”, en RODRÍGEZ ALONSO, Jaime, (ed), El Gran Hotel Pelayo de Covadonga, 1909-2009, Cien años de historia y turismo en el corazón de Asturias, $\mathrm{CH}$ Editorial Oviedo, 2009, p. 55.

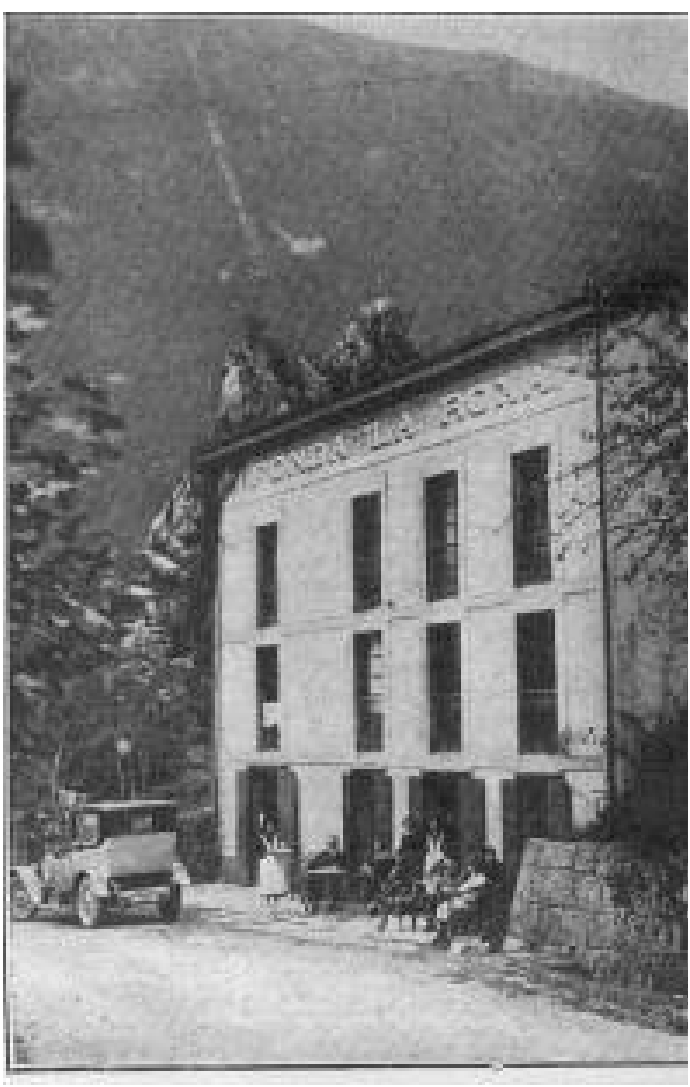

Fig. 5. Foto del anuncio de la fonda la Roxa. Asturias en la mano. 1925

la denominación de "Fonda Del Peregrino". La titularidad de este negocio la ostenta desde hace treinta años Vicente Cosío. En un anuncio publicitario de una guía turística del año 1924 puede leerse:

“FONDA Y RESTAURANT LA ROXA. Comedor espacioso, amplias y ventiladas habitaciones, cuarto de baño, luz eléctrica y timbres en toda la casa. Todas las instalaciones son modernas y elegantes. Garaje y servicio de automóvil. Frente al Santuario. Precios económicos". 44

Una foto del exterior aparece en ocasiones en su publicidad, acompañando a un texto muy parecido al citado. En el umbral, aparece un nutrido grupo de personas (podría tratarse de huéspedes o de la familia propietaria) cómodamente instalados en el clásico mobiliario de mimbre, acompañados por unas doncellas impecablemente uniformadas. El edificio que ocupa esta fonda, al borde de la carretera, de tres pisos, presenta

44 Asturias en la mano. Guía ilustrada de información general e interesante de la provincia, Sucesores de Rivadeneira, Madrid,1925. 
una fachada principal en la que se abren cuatro vanos por piso, todos balcones rasantes, con barandillas de hierro forjado. Bajo la cornisa, ocupando todo el frente, puede leerse Fonda "La Roxa”. Completa la imagen, el automóvil, probablemente del hotel, aparcado a la puerta.

Se trata de una evocadora secuencia que fija y perpetua para la historia un instante en el tiempo; y nos transporta a las primeras décadas del siglo XX y a unos alojamientos que ofrecían por primera vez al viajero y al peregrino unos servicios y unas instalaciones donde el confort y la hospitalidad eran marca de la casa, y donde el automóvil se había convertido en símbolo de modernidad. El trato personal y familiar se aliaban con unos equipamientos que habían incorporado las últimas mejoras en cuanto a servicios higiénicos se refiere y un amueblamiento acorde con unos estándares de calidad y buen gusto; un gran avance desde aquellos no muy lejanos tiempos de las diligencias donde mesones, posadas y ventas eran el recurso que el atribulado viajero tenía para descansar de las fatigas de los largos y penosos viajes.

\section{Conclusiones}

El análisis de los diferentes hospedajes que fueron surgiendo en torno al santuario de Covadonga en un recorrido a través del tiempo, ofrece la posibilidad de percibir con claridad la evolución que se va a ir produciendo en las diferentes fórmulas de hospitalidad desde los tiempos más remotos hasta la actualidad. El lugar es idóneo para este estudio. Pues la masiva presencia de romeros y peregrinos primero, y de viajeros y turistas después, va a ver desarrollar en torno a este espacio sagrado todo tipo de tipologías edificatorias, que reflejan los cambios que se producen en las condiciones de vida que se desarrollaban en torno a los viajes. Desde las tribulaciones de los romeros medievales que recorrían a pie largos trayectos en condiciones muy precarias y no necesitaban mucho más que la cama y el cobijo que proporcionaba la casa de las ánimas, edificio anejo al santuario, hasta la sofisticación y la complejidad del hotel Pelayo, que va a responder a unas necesidades muy diferentes, tanto de montañeros de élite, como de peregrinos y turistas.

Los diferentes ejemplos analizados en este artículo resultan además especialmente interesantes pues son todos ellos edificios que se construyen ex profeso para alojamiento, algo que no va a ser nada habitual en el resto del territorio astu- riano, donde fondas y hoteles ocupan uno o varias plantas de los edificios de viviendas de pisos, que a partir del último del siglo XIX, se construyen en ciudades y pueblos importantes, y tienen que adaptarse en mayor o medida al programa constructivo de la vivienda unifamiliar burguesa.

En Covadonga por el contrario encontramos modelos de edificación que responden a las necesidades de épocas y sociedades muy diferentes. De este modo la casa de novenas, es un amplio edificio de piedra y planta rectangular, situado muy cerca de la cueva, con abundantes vanos y buena ventilación para dar cobijo a los romeros, durante los nueve días de rezos que duran las novenas a la virgen. Es en este lugar donde se edifica en el siglo XVII un albergue de peregrinos junto a la comunidad de agustinos que en este momento custodia el santuario. Un siglo más tarde y al lado de la nueva carretera, se construye el mesón, en un edificio de sólida construcción y gran funcionalidad que consta de un amplio zaguán, corredor volado, y diferentes dependencias para comodidad de los viajeros. Y ya en las últimas décadas del siglo XIX se amplia y reforma la antigua hospedería aneja a la colegiata, instalándose en 1895 un comedor en la planta alta, signo inequívoco de los nuevos tiempos. Por último en la primera década del siglo XX se levantan dos de los establecimientos de hospedaje más emblemáticos: el hotel Pelayo, con todos los equipamientos de un hotel de lujo y el hostal Favila, para un público menos exigente, pero que contiene un programa funcional en la distribución de sus espacios, que resulta un ejemplo perfecto de edificio de viajeros.

Una constante que caracteriza la trayectoria de los hospedajes aquí analizados, es su titularidad, estrechamente vinculada a la iglesia, dado que todos ellos pertenecen al cabildo, si bien su explotación se va a poner en manos de excelentes profesionales de la hostelería que deberán en todo momento atenerse a las prescripciones de este espacio religioso. Los Acuerdos Capitulares están llenos de referencias en este sentido y dan cuenta de la cotidianidad y del día a día de dichos establecimientos; de los acuerdos y también de los desacuerdos que en algunas ocasiones se van a producir entre la iglesia y sus arrendatarios, que deberán en todo momento respetar el ambiente religioso del santuario.

Y para finalizar está la espectacular naturaleza del lugar, tan presente en Covadonga, y en sus proximidades, que va a llegar a definir en cierto modo la trayectoria de los propios hospedajes y también el devenir de un santuario que 
va a ser centro de devoción mariana y de turismo de naturaleza. Un paisaje que ha sido siempre protagonista, pues si el agua, la cueva y la abrupta orografía del monte Auseva hicieron posible la hazaña de Pelayo, en el año 722, y el inicio de la devoción mariana, también la creación del Parque de la Montaña de Covadonga, el 8 de septiembre de 1918, en el marco de los actos de conmemoración del XII Centenario de la Bata- lla de Covadonga, fue el inicio de un turismo de naturaleza que abrirá el santuario al turismo, por tanto a un nuevo público y con ello marcará el desarrollo de unos establecimientos orientados hasta entonces al peregrino.

ACC. Archivo Capitular de Covadonga AGPA. Archivo General del Principado de Asturias 
